\title{
Acid Blue 161: Decolorization and Toxicity Analysis After Microbiological Treatment
}

\author{
Erica Janaina Rodrigues de Almeida • \\ Carlos Renato Corso
}

Received: 11 April 2016 / Accepted: 16 August 2016 / Published online: 28 November 2016

(C) Springer International Publishing Switzerland 2016

\begin{abstract}
Concern for the incorrect disposal of potentially toxic substances in aquatic environments is growing due to adverse effects caused to the organisms exposed to them. Synthetic azo dyes are part of this group of substances, and increasingly, researchers seek alternatives able to degrade and remove these molecules to prevent their discharge to the environment. Thus, this study sought to examine the dye removal capacity Acid Blue 161 by biosorption and biodegradation from filamentous fungi Aspergillus niger and Aspergillus terreus and perform acute toxicity tests with Lactuca sativa organisms and Artemia salina. The biossorption treatment resulted in $46 \%$ decolorization of the solutions and reducing the toxicity of the means for both organisms tested. While the biodegradation study resulted in $84 \%$ decolorization at the end of treatment. The resulting solution of such treatment did not show toxicity to the larvae of $A$. salina and the $L$. sativa seeds were increased by $40 \%$ in the inhibition of root growth of seedlings. FTIR studies indicated the presence of amines in the middle, which justifies the increase in toxicity to seedlings, since these compounds are potentially toxic to a variety of organisms.
\end{abstract}

\footnotetext{
E. J. R. de Almeida $(\bowtie) \cdot$ C. R. Corso

Departamento de Bioquímica e Microbiologia,

UNESP - Universidade Estadual Paulista, Campus de Rio Claro, Instituto de Biociências, 24-A, ${ }^{\circ}{ }^{1515}$, CEP 13506-900 Bela Vista Rio Claro, SP, Brazil

e-mail: almeidaejr@gmail.com

C. R. Corso

e-mail: crcorso@rc.unesp.br
}

Keywords Textile effluent $\cdot$ Azo dyes $\cdot$ Microbiological treatments · Toxicity tests $\cdot$ Aspergillus $\mathrm{sp} \cdot \cdot$ L. sativa . A. salina

\section{Introduction}

The increasing pollution of aquatic environments is the topic of discussion worldwide and has led to the search for the effective treatment of chemicals that are harmful to these ecosystems (Horvat et al. 2012). It is estimated that about 100,000 different synthetic dyes and pigments are produced commercially, being that the azo dyes are an important class of environmental contaminants, corresponding 60-70\% of total production (Baêta et al. 2015; Imran et al. 2016). These dyes are also extensively employed in the textile industry and have a complex structure that contains one or more azo bonds $(-\mathrm{N}=\mathrm{N}-)$, are hard to degrade in biological aerobic conditions and are also resistant into natural environments (Couto 2009; Athalathil et al. 2015).

Treatment of textile effluents is of considerable importance due to the toxic and esthetic impacts of these pollutants on water bodies. In addition, these pollutants can be transferred to the food chain and thus are threatening human health (Guendouz et al. 2013). Although many studies have sought to develop effective treatments technologies for wastewater containing azo dyes, no single solution is able to remedy the great diversity of textile waste satisfactorily.

Biological treatments have emerged as an effective, environmentally friendly alternative capable of the 
partial or complete bioconversion of pollutants, resulting in non-toxic products (Pakshirajan et al. 2011). The evaluation of the toxicity of azo dyes is also of extreme importance, because the harmful effects of these substances in aquatic environments goes far beyond visual pollution, as these dyes contains amines and benzidines in their molecular structure and the release of these compounds constitutes a high potential for toxicity in the form of metabolites stemming from the degradation process ( $\mathrm{Al}$ et al. 2013).

This research aimed to the search by techniques for the treatment of textile wastewater, which assessed biosorption and biodegradation of the azo dye Acid Blue 161 in solutions containing the filamentous fungi A. niger and A. terreus. The acute toxicity of these solutions was evaluated before and after microbiological treatment using seedlings from $L$. sativa and A. salina larvae.

\section{Materials and Methods}

\subsection{Azo dye Acid Blue 161}

The azo dye Acid Blue 161 (CAS 12392-64-2, see Fig. 1) was obtained from the Aldrich Chemical Company, Inc. Acid Blue 161 is water soluble, with $\lambda_{\max }=$ $602.5 \mathrm{~nm}, \mathrm{FW} 416.39$ and $40 \%$ dye content.

\subsection{Microorganisms}

Biosorption and biodegradation tests were respectively performed with the filamentous fungi $A$. niger (CCT 1435) and A. terreus (CCT 2679) obtained from the culture collection of André Tosello Foundation for Research and Technology. The fungi were used in their paramorphogenic physical form, using the pelletizing method proposed by Marcanti-Contato et al. (1997). The choice of fungi for biosorption and biodegradation treatments was determined in preliminary experimental tests.

\subsection{Biosorption}

The decolorization of solutions composed of Acid Blue 161 by biosorption was performed in $100 \mathrm{~mL}$-Erlenmeyer flasks containing $25 \mathrm{~mL}$ of dye solution at a concentration of $200 \mu \mathrm{g} \mathrm{mL}^{-1}, \mathrm{pH} 4.0$, and $5 \mathrm{mg} \mathrm{mL}^{-1}$ of pelleted $A$. niger biomass. The flasks were incubated at $30 \pm 1{ }^{\circ} \mathrm{C}$ for $3 \mathrm{~h}$. Decolorization of the solutions was monitored by UV-Vis spectrophotometry (Shimadzu 2401 PC). After the period of contact between the adsorbent biomass and dye, the solutions were centrifuged at $5000 \mathrm{rpm}$ for $10 \mathrm{~min}$. UV-Vis analyses were performed in the 720 to $240 \mathrm{~nm}$ range. The degree of decolorization was calculated from the results of absorbance at $\lambda_{\max }=602.5 \mathrm{~nm}$.

\subsection{Biodegradation}

Biodegradation of the azo dye was performed in aqueous solution containing $A$. terreus in $100 \mathrm{~mL}$ Erlenmeyer flasks containing $25 \mathrm{~mL}$ of dye solution at a concentration of $200 \mu \mathrm{g} \mathrm{mL}^{-1}, \mathrm{pH} 4.0$, sterilized by autoclaving at $120{ }^{\circ} \mathrm{C}$, and 1 atm for $20 \mathrm{~min}$. Fungal biomass pellets $\left(3 \mathrm{mg} \mathrm{mL}^{-1}\right)$ were transferred aseptically to each flask, which were then incubated at $30 \pm 1{ }^{\circ} \mathrm{C}$. The samples were analyzed by UV-Vis spectrophotometry and FTIR spectroscopy after 24, 240 , and $336 \mathrm{~h}$ of treatment.

The experimental results of the biosorption and biodegradation tests were expressed as the percentage of decolorization, which was obtained from Eq. (1).
Fig. 1 Molecular structure of Acid Blue 161

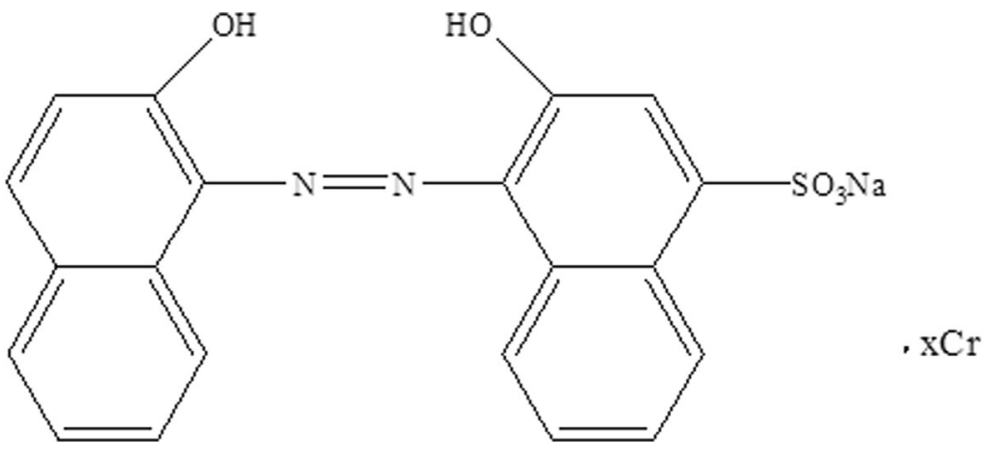


$\%$ Decolorization

$$
\begin{aligned}
= & \frac{(\lambda \max 602,5 \mathrm{~nm} \text { initial }-\lambda \max 602,5 \mathrm{~nm} \text { final })}{\lambda \max 602,5 \mathrm{~nm} \text { initial }} \\
& \times 100
\end{aligned}
$$

\subsection{FTIR Analysis of Metabolites Formed During Biodegradation}

FTIR analysis (Shimadzu FTIR-8300) was also performed to obtain more detailed information on the transformation of the dye following biodegradation. FTIR spectra provide information on the molecular structure, and this method is a useful tool in the analysis of metabolites formed after the biotransformation of dye molecules. Samples were dried at $105^{\circ} \mathrm{C}$. $\mathrm{KBr}$ discs were prepared at a ratio of $1 \mathrm{mg}$ of sample to $149 \mathrm{mg}$ of $\mathrm{KBr}$. The discs were placed in suitable holders and readings were performed in the mid-infrared region (400-4000 $\mathrm{cm}^{-1}$ ) with 16 scans at a resolution of $4 \mathrm{~cm}^{-1}$.

\subsection{Phytotoxicity Assessment Using Seedlings from $L$ sativa}

The phytotoxicity test was used to determine the inhibition of root growth of $L$. sativa seedlings (TopSeed® Garden) before and after the biosorption and biodegradation treatments. For such, Petri dishes were lined with filter paper, to which 20 seedlings and $3 \mathrm{~mL}$ of the test solution were added. The plates were individually wrapped in plastic film to avoid the evaporation of moisture and placed in a climatic chamber at $21 \pm 1{ }^{\circ} \mathrm{C}$ in the absence light for $72 \mathrm{~h}$. The positive control was $\mathrm{ZnSO}_{4} 0.05 \mathrm{~N}$ and the negative control was distilled water. Untreated dye solutions at a concentration of $200 \mu \mathrm{g} \mathrm{mL} \mathrm{m}^{-1}$ were also tested. At the end of the exposure period, measurements of the roots were taken and growth inhibition was calculated using Eq. (2).

\section{$\%$ Inhibition}

$$
\begin{gathered}
=\frac{\text { root growth negative control-root growth dye solution }}{\text { root growth negative control }} \\
\times 100
\end{gathered}
$$

\subsection{Toxicity Assessment Using A. salina Larvae}

The toxic effect was determined by the mortality of brine shrimp (A. salina) larvae after $48 \mathrm{~h}$ of exposure to the Acid Blue 161 solutions before and after biosorption and biodegradation. A. salina larvae were obtained after hatching from dry eggs in artificial sea water with constant aeration. Recently, hatched (24 h) larvae were used for the tests, which were performed in test tubes containing $2 \mathrm{~mL}$ of artificial sea water and $3 \mathrm{~mL}$ of dye solution, totaling $5 \mathrm{~mL}$ of test solution. Artificial sea water was used as the control. After preparation of the tubes, 10 larvae were added and were left exposed to the solutions (untreated Acid Blue 161 and solutions following the microbiological treatments) for $48 \mathrm{~h}$, after which the mortality rate was calculated.

\section{Results and Discussion}

\subsection{Biosorption Analysis}

Biosorption by $A$. niger achieved $46 \%$ decolorization of Acid Blue 161 in the solutions after $3 \mathrm{~h}$ of contact with the adsorbent, indicating a high degree of affinity of the dye molecules to the fungal biomass. Dye removal from the reaction medium occurred with no significant structural changes in the molecules, as the UV-Vis spectrum remained virtually unchanged after biosorption treatment in comparison to the pretreatment analysis (see Fig. 2).

Considering the high sensitivity of plants to toxic substances (Sobrero and Ronco 2008), the acute phytotoxicity test performed with $L$. sativa seedlings revealed a change in toxicity of the medium following the biosorption treatment, with a reduction in root growth inhibition from approximately $9.2 \%$ (control solution: $200 \mu \mathrm{g} \mathrm{mL}^{-1}$ ) to $0 \%$. Table 1 displays the root growth data of the $L$. sativa seedlings. Regarding A. salina larvae, no toxicity occurred either before or after decolorization treatment with the fungal biomass.

The toxicity results offer evidence that no degradation of the molecules occurred during the decolorization process, as treatment occurred without the production of metabolites with toxic potential. These findings reveal that the biosorption process was effective in reducing both the decolorization and toxicity of the solutions.

Kabbout and Taha (2014) studied the biosorption dye of Methylene Blue and showed a efficient 
Fig. 2 UV-Vis spectrum of Acid Blue 161 before and after biosorption with $A$. niger

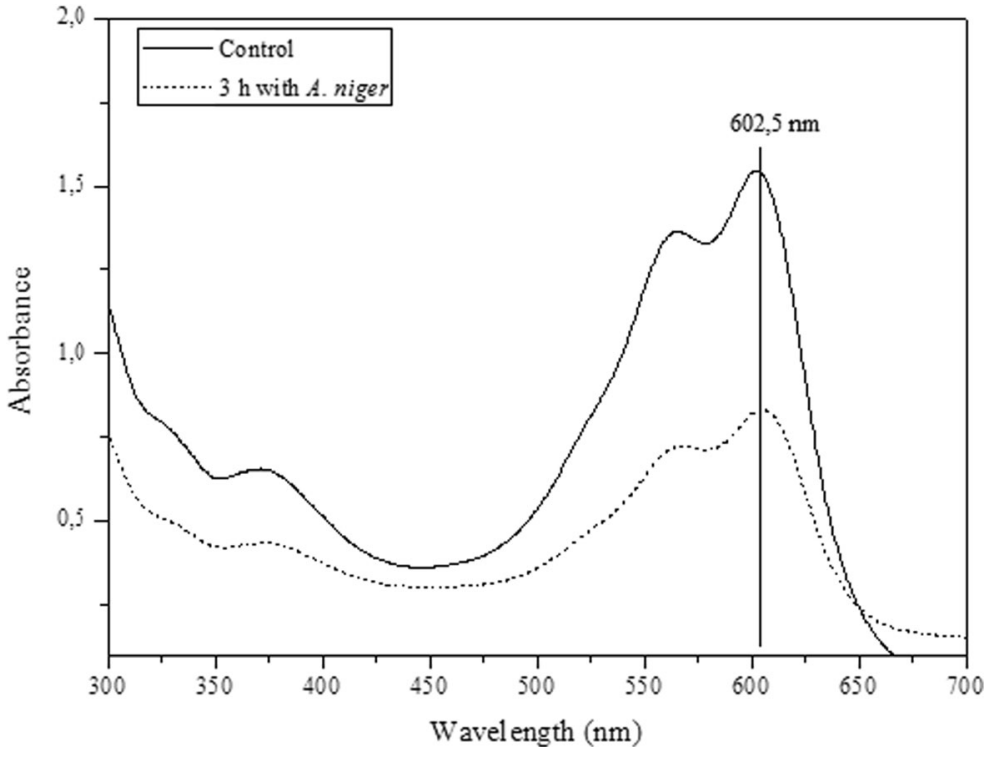

decolorization with fungal biomass of Aspergillus fumigatus. They found that the rapid dye biosorption occurred in $30 \mathrm{~min}$ reaching $58 \%, 68 \%$ in $120 \mathrm{~min}$ and reaching a maximum of $71 \%$ in $210 \mathrm{~min}$ and remaining constant. Therefore, $180 \mathrm{~min}$ of treatment used in this study can be determined as the optimum contact time in biosorption treatments.

\subsection{Biodegradation Analysis}

Biodegradation of Acid Blue 161 in by the fungus A. terreus achieved $84 \%$ decolorization of the solutions. Moreover, significant spectral changes occurred upon biotransformation of Acid Blue 161 molecules (see Fig. 3).

Table 1 Root growth in L. sativa seedlings before and after biosorption treatment with $A$. niger

\begin{tabular}{llll}
\hline Test solution & $\begin{array}{l}\text { Decolorization } \\
(\%)\end{array}$ & $\begin{array}{l}\text { Mean } \\
\text { root } \pm \text { standard } \\
\text { deviation }(\mathrm{cm})\end{array}$ & $\begin{array}{l}\text { Inhibition } \\
(\%)\end{array}$ \\
\hline $\begin{array}{c}\text { Negative } \\
\text { control } \\
\text { (distilled }\end{array}$ & 0 & $0.76 \pm 0.02$ & 0 \\
$\begin{array}{c}\text { water) } \\
\text { Dye solution } \\
\text { before } \\
\text { treatment }\end{array}$ & 0 & $0.69 \pm 0.08$ & 9.2 \\
$\begin{array}{c}\text { Dye solution } \\
\text { after } \\
\text { treatment }\end{array}$ & 46 & $0.77 \pm 0.04$ & 0.00 \\
\hline
\end{tabular}

In the acute phytotoxicity test with $L$. sativa seedlings, increases of 51.8 and $69 \%$ root growth inhibition were found in seedlings exposed to solutions treated for 24 and $240 \mathrm{~h}$, respectively. In the solutions treated for $336 \mathrm{~h}$, toxicity was decreased by approximately $30 \%$ in comparison to solutions treated for $240 \mathrm{~h}$ (Fig. 4).

The increased toxicity indicates that biodegradation of the dye molecules led to the formation of metabolites (Isik and Sponza 2007) that were highly toxic to the developing $L$. sativa seedlings. However, the subsequent reduction in toxicity after $336 \mathrm{~h}$ of treatment is an indication that the metabolites formed from the breakdown of the molecules also began to become degraded by the microorganism.

A. salina has been used as a bioindicator of the toxicity of textile effluents (Ayed et al. 2011), since the high degrees of salinity and conductivity in these effluents are critical parameters for freshwater species. Analyzing the results of toxicity to A. salina, a slight increase in larval mortality was found after exposure to solutions treated for 24 and $240 \mathrm{~h}$, demonstrating that the metabolites formed in this timeframe were harmful to the organisms. Regarding the solutions treated for $336 \mathrm{~h}$, the findings demonstrate that the biodegradation treatment was no longer toxic to A. salina larvae (Fig. 5).

The toxicity data indicate that dye degradation was incomplete and released harmful metabolites into the medium. The reduction in toxicity after $336 \mathrm{~h}$ of treatment is an indication that the secondary metabolites formed during treatment also began to become degraded 
Fig. 3 UV-Vis spectrum of Acid Blue 161 before and after biodegradation treatment with A. terreus

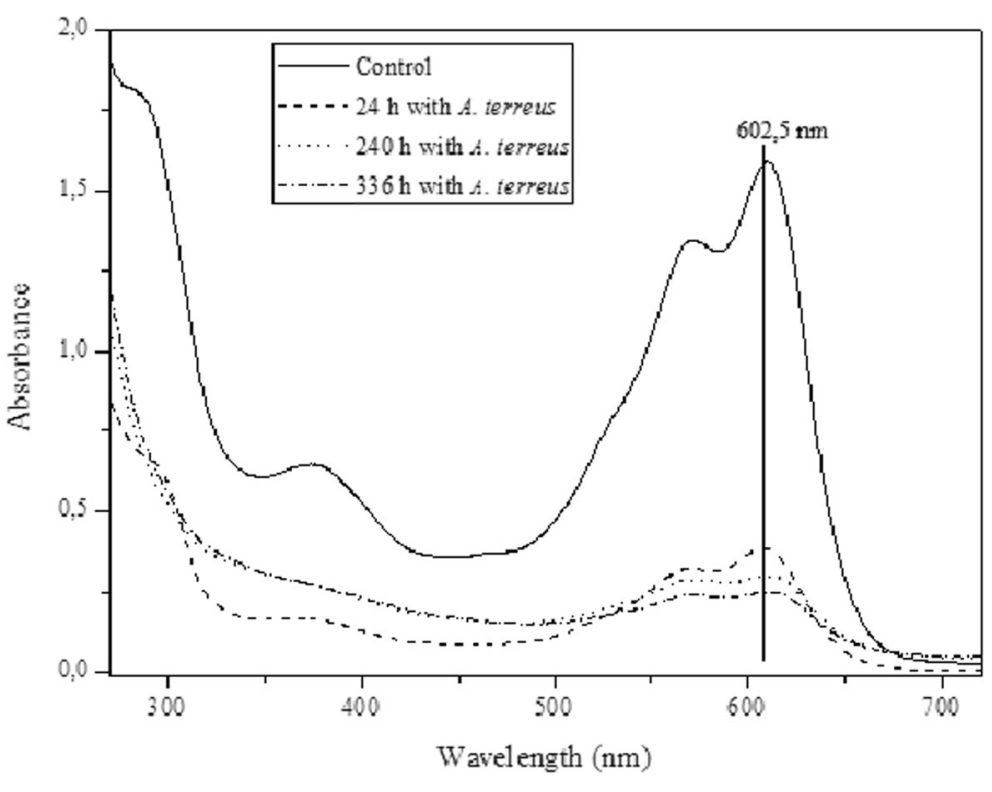

by the microorganism. These findings underscore the fact that the toxicity of treated effluents after decolorization must be considered before their discharge into the environment, as the absence of color does not necessarily mean a lack of toxicity and that the effluent is ready for disposal.

\subsection{FTIR Analysis of Metabolites Formed During Biodegradation}

The FTIR spectra demonstrate the dye structures in greater detail. In the comparison of the control Acid Blue 161 solution and those subjected to the biodegradation treatment, sharp spectral changes were found after contact with the biomass pellets of $A$. terreus. The analysis of these spectra allows estimating what compounds were likely formed after the degradation of the dye molecules. Figure 6 displays the spectra before and after microbiological treatment.

The main changes occurred in the region spanning from 2000 to $400 \mathrm{~cm}^{-1}$. In the spectra after 24, 240 and $336 \mathrm{~h}$ of treatment, significant changes were found in the $1640-1463 \mathrm{~cm}^{-1}$ region, which is characteristic of the presence of $\mathrm{N}-\mathrm{H}$ bending in the amine and azo groups. The increased intensity of the bands in this region indicates that the possible occurrence of the cleavage of azo
Fig. 4 Root growth inhibition in L. sativa seedlings before and after biodegradation treatment with A. terreus

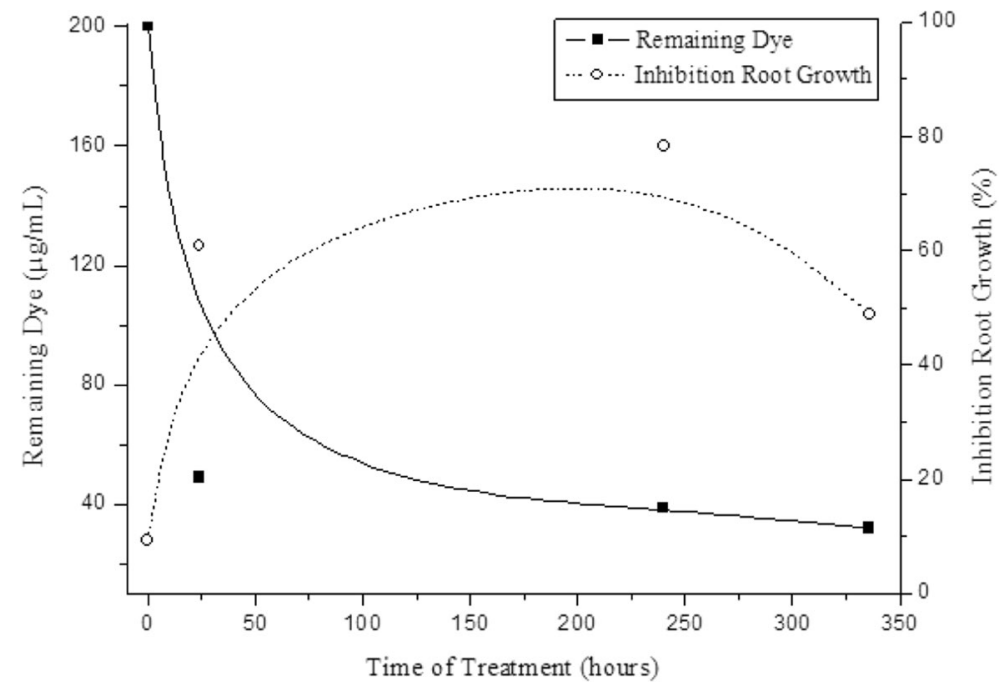


Fig. 5 Mortality rate of $A$. salina larvae before and after biodegradation treatment with A. terreus
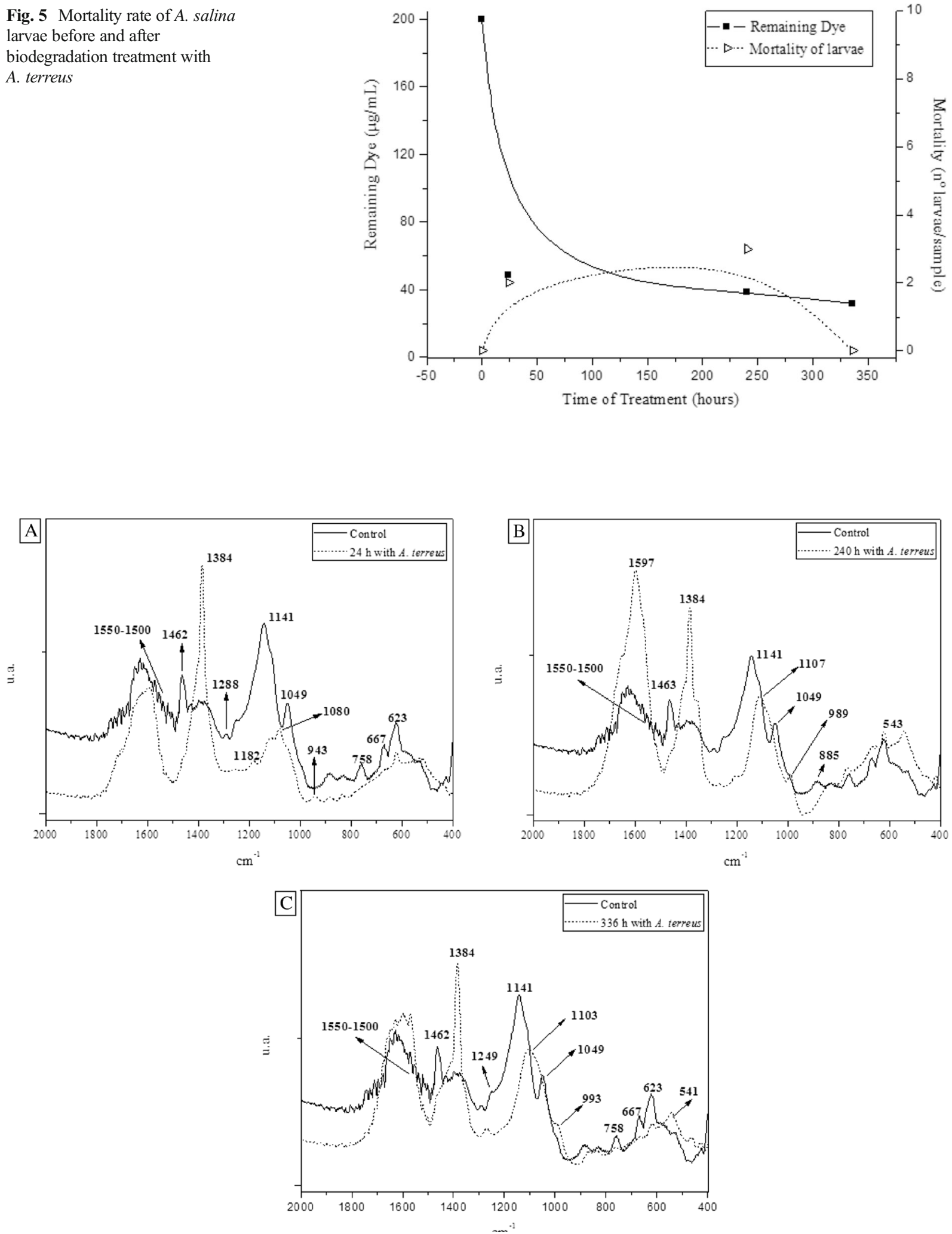

Fig. 6 FTIR spectra of Acid Blue 161 before and after a $24 \mathrm{~h}$ of treatment, b $240 \mathrm{~h}$ of treatment, and c $336 \mathrm{~h}$ of treatment with A. terreus 
bonds promoted by the action of the azoreductases, releasing amine molecules as byproducts (Olukanni et al. 2010; Rathod and Archana 2013; Amin et al. 2015). The band in region at $1384-1380 \mathrm{~cm}^{-1}$ corresponds to $\mathrm{C}-\mathrm{H}$ bending and stretching of $-\mathrm{CH} 3$ of the dye molecules (Du et al. 2012). The band for $\mathrm{S}=\mathrm{O}$ stretching at $1141 \mathrm{~cm}^{-1}$ and vibrations of $\mathrm{C}-\mathrm{OH}$ bonds at $1049 \mathrm{~cm}^{-1}$ present in the naphthol group was observed (Bedekar et al. 2014; Babu et al. 2015). All treatments caused a reduction in the intensity of these bands, possibly indicating the breakage of these bonds during the biodegradation process.

After $24 \mathrm{~h}$ of treatment, the FTIR spectrum showed the appearance of bands at 1080 and $941 \mathrm{~cm}^{-1}$ corresponding to the vibration of $\mathrm{C}-\mathrm{N}$ and $\mathrm{N}-\mathrm{H}$ bonds of secondary amines (Ayed et al. 2010). After $240 \mathrm{~h}$ of treatment, the intensification in the 1597 and $1107 \mathrm{~cm}^{-1}$ regions corresponds to the $\mathrm{C}=\mathrm{C}$ of aromatic rings and primary amines, respectively (Arjunan et al. 2004; Fanchiang and Tseng 2009; Ayed et al. 2010; Olukanni et al. 2010).

All structural changes evident in the FTIR spectra indicate that Acid Blue 161 molecules were degraded by the enzymatic action of the fungus A. terreus, and this degradation led to the formation of different secondary metabolites, such as primary and secondary amines. Figure 7 displays a hypothetical incomplete degradation scheme for the dye molecules and their possible metabolites.

\section{Conclusions}

In this research, the biosorption treatment was effective in reducing both the decolorization and toxicity of the solutions. The biodegradation process demonstrated considerable ability in decolorizing the solutions, but led to the formation of metabolites that were mainly toxic to the $L$. sativa seedlings. The degradation of the secondary metabolites formed during the biotransformation of dye molecules was evident at the end of the treatment, when the solutions became less toxic to L. sativa seedlings and were non-toxic to the A. salina larvae. Thus, from the toxicological point of view, it is better to remove dye molecules from the medium through biosorption, as the period of contact with the microorganism is reduced, decolorization occurs without major molecular changes and there is no formation of metabolites with potential toxicity. Although biodegradation treatment also proved effective in decolorizing the solutions, this process should be accompanied by a longer period until the degradation of the metabolites formed during microbiological treatment. Thus, we observed that there was no mineralization of dyes, but the data generated in the present study are relevant to the advancement of studies on the biosorption and biodegradation of synthetic dyes, especially with filamentous fungi.
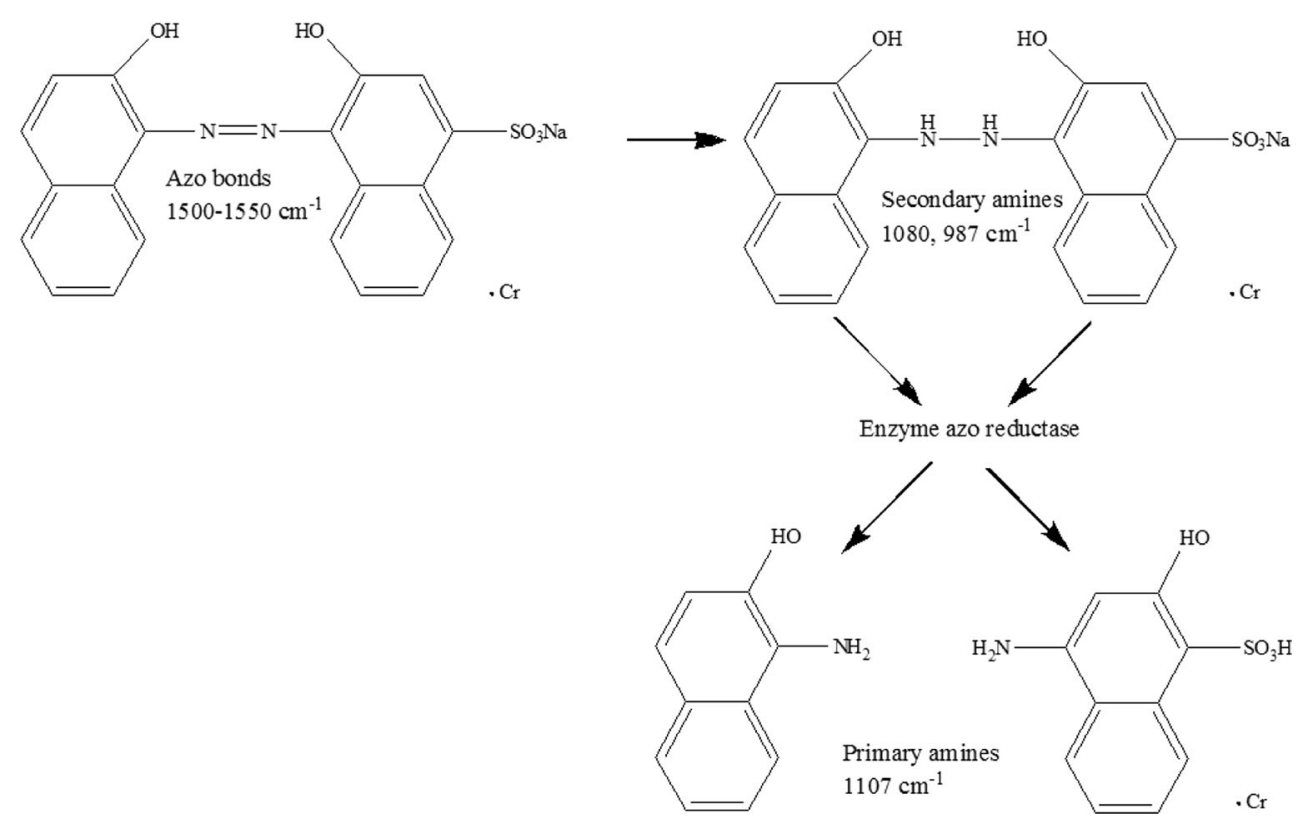

Fig. 7 Proposed degradation pathways for azo dye Acid Blue 161 by A. terreus 
Acknowledgments Support from the Brazilian fostering agencies FAPESP/Brazil, CAPES/Brazil, CNPq/Brazil and Fundunesp/Brazil.

\section{References}

Al, G., Özdemir, U., \& Aksoy, Ö. (2013) Cytotoxic effects of Reactive Blue 33 on Allium cepa determined using Taguchi's $\mathrm{L}_{8}$ orthogonal array Ecotoxicology and Environmental Safety, 98, 36-40.

Amin, F., Talpur, F. N., Balouch, A., Surhio, M. A., \& Bhutto, M. A. (2015). Biosorption of fluoride from aqueous solution by white-rot fungus Pleurotus eryngii ATCC 90888. Environmental Nanotechnology Monitoring \& Management, 3, 30-37.

Arjunan, V., Subramanian, S., \& Mohan, S. (2004). FTIR and FTR spectral studies of 2-amino-6-bromo-3-formylchromone. Spectrochimica Acta A, 60, 995-1000.

Athalathil, S., Font, J., Fortuny, A., Stüber, F., Bengoa, C., \& Fabregat, A. (2015). New sludge-based carbonaceous materials impregnated with different metals for anaerobic azo-dye reduction. Journal Environmental Chemical Engineering, 3, 104-112.

Ayed, L., Chaieb, K., Cheref, A., \& Bakhrouf, A. (2010). Biodegradation and decolorization of triphenylmethane dyes by Staphylococcus epidermidis. Desalination, 260, 137-146.

Ayed, L., Mahdhi, A., Cheref, A., \& Bakhrouf, A. (2011). Decolorization and degradation of azo dye Methyl Red by an isolated Sphingomonas paucimobilis: biotoxicity and metabolites characterization. Desalination, 274, 272-277.

Babu, S. S., Mohandass, C., Vijayaraj, A. S., \& Dhale, A. M. (2015). Detoxification and color removal of Congo red by a novel Dietzia sp. (DTS26) - a microcosm approach. Ecotoxicology and Environmental Safety, 144, 52-60.

Baêta, B. E. L., Lima, D. R. S., Silva, S. Q., \& Aquino, S. F. (2015). Evaluation of soluble microbial products and aromatic amines accumulation during a combined anaerobic/aerobic treatment of a model azo dye. Chemical Engineering Journal, 259, 936-944.

Bedekar, P. A., Saratale, R. G., Saratale, G. D., \& Govindwar, S. P. (2014). Development of low cost upflow columm bioreactor for degradation and detoxification of blue HERD and textile effluent by Lysinibacillus sp. RGS immobilized on Loofa. International Biodeterioration \& Biodegradation, 96, 112-120.

Couto, S. R. (2009). Dye removal by immobilised fungi. Biotechnology Advances, 27, 227-235.
Du, L. N., Wang, B., Li, G., Wang, S., Crowley, D. E., \& Zhao, Y. H. (2012). Biosorption of the metal-complex dye Acid Black 172 by live and heat-treated biomass of Pseudomonas sp. strain DY1: kinetics and sorption mechanisms. Journal of Hazardous Materials, 205-206, 47-54.

Fanchiang, J. M., \& Tseng, D. H. (2009). Degradation of anthraquinone dye C.I. Reactive Blue 19 in aqueous solution by ozonation. Chemosphere, 77, 214-221.

Guendouz, S., Khellaf, N., Zerdaoui, M., \& Ouchefoun, M. (2013). Biosorption of synthetic dyes (Direct Red 89 and Reactive Green 12) as an ecological refining step in textile effluent treatment. Environmental Science and Pollution Research, 20, 3822-3829.

Horvat, A. J. M., Petrovic, M., Babics, S., Pavlovic, D. M., Asperger, D., Pelko, S., Mance, A. D., \& Kastelan-Macan, M. (2012). Analysis, occurrence and fate anthelmintes and their transformation products in the environment. Trends in Analytical Chemistry, 31, 61-24.

Imran, M., Arshad, M., Negm, F., Khalid, A., Shaharoona, B., Hussain, S., Nadeem, S. M., \& Crowley, D. E. (2016). Yeast extract promote decolorization of azo dyes by stimulating azoreductase activity in Shewanella sp, strain IFN 4. Ecotoxicology and Environmental Safety, 124, 42-49.

Isik, M., \& Sponza, D. T. (2007). Fate and toxicity of azo dye metabolites under batch long-term anaerobic incubations. Enzyme and Microbial Technology, 40, 934-939.

Kabbout, R., \& Taha, S. (2014). Biodecolorization of textile dye effluent by biosorption of fungal biomass materials. Physics Procedia, 55, 437-444.

Marcanti-Contato, I., Corso, C. R., \& Oliveira, J. E. (1997). Induction of physical paramorfogenesis in Aspergillus sp. Revista de Microbiologia, 28, 65-67.

Olukanni, O. D., Osuntoki, A. A., Kalyani, D. C., Gbenle, G. O., \& Govindwar, S. P. (2010). Decolorization and biodegradation of Reactive Blue 13 by Proteus mirabilis LAB. Journal of Hazardous Materials, 184, 290-298.

Pakshirajan, K., Sivasankar, A., \& Sahoo, N. K. (2011). Decolourization of synthetic wastewater containing azo dyes by immobilized Phanerochaete chrysosporium in a continuously operated RBC reactor. Applied Microbiology and Biotechnology, 89, 1223-1232.

Rathod, J., \& Archana, G. (2013). Molecular fingerprinting of bacterial communities in enriched azo dye (Reactive Violet 5R) decolorising native acclimatised bacterial consortia. Bioresourse Technology, 142, 436-444.

Sobrero, M. S., \& Ronco, A. (2008). Ensayo de toxidad aguda con semillas de lechuga Lactuca sativa L. Ensayos toxicológicos pra la evalucion de susbstancias químicas en agua y suelo, 1 , 55-68. 